\title{
Jedem seine Macke
}

_ In gut einem Monat ist Weihnachten. Bei mir bedeutet das: Meine Mutter erliegt einem mysteriösen Plätzchenbackwahn, und sie wird unzählige Plätzchen herstellen. Mit Nüssen, mit Rosinen, mit Hagelzucker, sogar mit Essig!

_. Als ich letztes Jahr Heiligabend zu Hause ankam, schickte sie mich als erstes in den Vorratskeller, um ihre Plätzchen zu probieren. Sie hatte sich dieses Mal selbst übertroffen und präsentierte mir 18 Sorten! Ich begann mit den Butterknöpfchen links außen, arbeitete mich dann bis zu den Vanillekipferln vor und hatte nach acht weiteren Sorten das Ziel (Hafertaler) erreicht.

_ Oh ja, ihre Plätzchen schmecken prima. Und als Ergotherapeutin habe ich oft davon profitiert. Ich hatte immer ein tolles Rezept parat, wenn ich eine Backgruppe leitete. Aber ganz ehrlich: Für wen bäckt sie diese Massen? Meine Geschwister und ich kommen schließlich nur über die Feiertage nach Hause ...

_ Egal, was wir zu dem Backwahn sagen - es ändert sich nichts. Ich hatte es sogar schon ganz ergotherapeutisch probiert und mit meiner Mutter einen Plan erstellt. Das Ziel lautete: dieses Jahr nur sechs Sorten backen. Jeder Familienangehörige durfte sich eine Sorte wünschen. Allerdings interpretierte meine Mutter den Begriff „Familienangehörige“ sehr frei, denn zum Schluss standen zwölf Sorten auf dem Tisch! Mittlerweile haben wir Kinder begriffen, dass diese Macke zu unserer Mutter gehört wie Plätzchen zu Weihnachten.

_ Demnächst werde ich wieder meinen Koffer packen und heimfahren. Und irgendwie - muss ich zugeben - freue ich mich schon darauf, an Heiligabend die Keksdosen zu öffnen, hineinzugreifen und dann ganz fachmännisch zu verkosten. So mancher Spleen enthält auch viel Gutes. Wenn ich nur an die herrlichen Eischneeplätzchen denke ...

_ Ebenfalls viel Vorfreude auf die Feiertage wünscht Ihnen

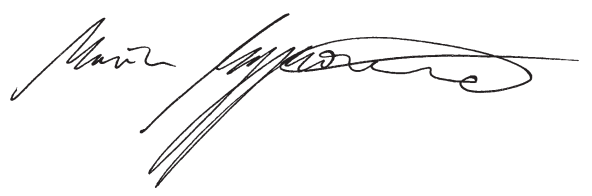

PS: Ein feines Plätzchenrezept finden Sie übrigens auf unserer Facebook-Seite www.facebook.com/thiemeliebtergotherapeuten.
ZU GEWINNEN

Kursplatz

1 Kurs „Manuelle Lymphdrainage

für Ergotherapeuten“ Seite 45

Bücher

$4 \mathrm{x}$ „Stressfrei durch

Progressive Relaxation“ Seite 22

Und außerdem...

1 Stimmgabel

Seite 30

1 Karte für den 7. ergotag Seite 39

1 Venezianisches

Solitärspiel

Seite 51

1 Prometheus-Set mit Bag,

Buch und Duschvorhang Seite 51

3 Sanddorn-Wellness-Sets Seite 51

3 Kalender

Seite 51

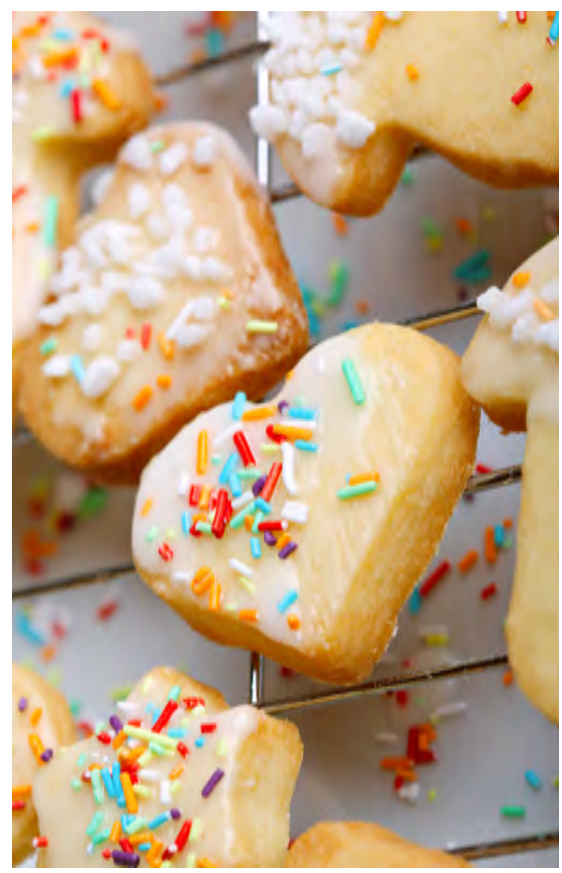

